\title{
NBSIR 85-3209
}

\section{Radiation Measurements on $A$ Portable 1.5 MEV Electron Linac}

C.E. Dick, D. Polansky, C.G. Soares, and S.M. Seltzer

U.S. DEPARTMENT OF COMMERCE

National Bureau of Standards

Center for Radiation Research

Gaithersburg, MD 20899

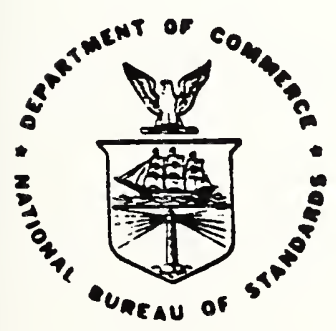

U.S. DEPARTMENT OF COMMERCE

NATIONAL BUREAU OF STANDARDS 

NBSIR 85-3209

RADIATION MEASUREMENTS ON A PORTABLE 1.5 MEV ELECTRON LINAC

C.E. Dick, D. Polansky, C.G. Soares, and S.M. Seltzer

U.S. DEPARTMENT OF COMMERCE

National Bureau of Standards

Center for Radiation Research

Gaithersburg, MD 20899

September 1985

U.S. DEPARTMENT OF COMMERCE, Malcolm Baldrige, Secretary NATIONAL BUREAU OF STANDARDS. Emest Ambler, Director 
Radiation Measurements on a Portable 1.5-MeV Electron Linac

C.E. Dick, D. Polansky, C.G. Soares, and S.M.Seltzer Center for Radiation Research

National Bureau of Standards

Gaithersburg, MD. 20899

April 30, 1985 



\section{ABSTRACT}

We have carried out an exhaustive series of measurements on the properties of a $1.5 \mathrm{MeV}$ electron linac designed for radiographic applications. Measurements of the focal spot size, central axis radiation intensity, radiation field uniformity, beam penetration, and radiation leakage have been made to characterize the source. Additionally, Monte Carlo calculations of the source output have been made to determine if the geometry is amenable to a theoretical analysis. Although these data pertain to a particular radiation source, the techniques described are applicable to the characterization of a large class of radiation producing devices. 



\section{INTRODUCTION}

This report details measurements made on the radiation characteristics of a $1.5 \mathrm{MeV}-$ electron Iinac. The main purpose of this report is to outline the procedures used to characterize radiation sources for possible applications in high energy radiography. The accelerator we have used is a commercial unit manufactured by the Schonberg Radiation Corporation in Mountain View, California (Minac Model $\mathrm{T}-1500)^{1,2}$ and is designed for use in portable radiographic applications. We have investigated the operation and the properties of the radiation field produced by this device. These measurements have been divided into a number of tasks designed to measure the pertinent parameters of this source including the radiation intensity, the focal spot size, the field uniformity, the beam quality, and the radiation leakage. Additionally, based on the physical characteristics of the electron beam and x-ray converter, Monte Carlo calculations of the $x$-ray spectrum have been carried out. In the sections that follow, each of these topics is discussed in detail. The accelerator consists of four basic modules which can be disconnected for transport. These modules are the control console, the x-ray head, the rf modulator and circulator, and the power unit. The accelerator was installed in a radiation shielded vault for personnel shielding. The initial setup of the accelerator took two people approximately four hours. This time would undoubtedly be reduced as familiarity is gained with the instrument.

The $\mathrm{x}$-ray head contains the electron source, $\mathrm{x}$-ray target, 
and rf accelerating structure. This unit is provided with a vacion vacuum pump to provide the necessary high vacuum, and electrostatic beam steerers to center the electron beam on the $\mathrm{x}-$ ray target. $\mathrm{RF}$ power for acceleration of the electrons is provided by the rf-modulator chassis which is connected to the $\mathrm{x}-$ ray head with a flexible rf-waveguide. After the instrument was assembled, the power supply and vacion pump were energized. After approximately 5 minutes, the vacuum indicator read less than I microamp indicating that a good vacuum was obtained, and the vacuum interlock light on the console indicated a good vacuum status (lamp lit).

Upon completion of the above installation, the accelerator was left powered (except for the high voltage) for the duration of the testing period. Initially, no measurements were made for 24 hours to ensure that the vacuum in the accelerator was well established. All measurements discussed below were made with the following settings to provide reproducibility: AC input power variac maximum clockwise (meter indicates approximately 125 volts); accelerator heater control set at 80 as recommended in manufacturers operation manual; beam steerers both minimum (counterclockwise) in REV position. These controls do deflect the beam as can be seen in measurements of the radiation output on the central axis, but the effect is less than $5 \%$ in output and it was deemed desirable to have a reproducible setting of these controls at the expense of slightly higher output. It was noticed that the output exhibited a systematic increase for the first few days of operation. This may be due to the effects of a higher vacuum or a cleaning up of the accelerator structure. 


\section{MEASUREMENT OE FOCAL SPOT SIZE}

In order to measure the size of the electron beam on the $x-$ ray target, the geometry of Figure 1 was employed. A $1 \mathrm{~mW}$ He-Ne laser was used to define the central axis of the accelerator. The laser was located approximately 5 meters from the x-ray target and was left in place for all of the measurements to define the central axis of the radiation field. Reflection of the laser beam from a mirror mounted on the $\mathrm{x}$-ray target indicated that the laser was coincident with the central axis of the accelerator to at least 0.1 degrees. A Pt-Au collimator with a thickness of $3 \mathrm{~mm}$ and containing a $300-\mu \mathrm{m}$ hole was placed 0.5 meter from the $\mathrm{x}-$ ray target. The pinhole was aligned on the axis using the laser beam. A shielded $\mathrm{x}$-ray film cassette was placed at a distance of 1 meter from the $x$-ray source. This geometry provides unit magnification of the image of the focal spot.

The film cassette contained a $125-\mu \mathrm{m}$ thick lead front screen, Kodak type $M$ industrial radiographic film 1 , and a $250-\mu \mathrm{m}$ thick lead back screen to record the image of the pinhole. Images of the pinhole were made on the film for times of 4,8 , and 12 minutes at the full output of the accelerator. Visual measurements of the focal spot image with a measuring magnifier indicates that the focal spot is nearly round with a diameter of approximately $3 \mathrm{~mm}$.

In order to verify this measurement, the radiograph was placed in a scanning microdensitometer and the film scanned in two orthogonal directions. The results of these scans are shown in Fig. 2. These data indicate that the size of the focal spot 
Figure 1. Schematic drawing of the geometry used for the measurement of the electron focal spot on the x-ray target. The dotted center line represents the beam from a He-Ne laser located 5 meters from the target. This geometry is typical of that used for all of the measurements on the accelerator with the laser beam being used to define the beam axis. 


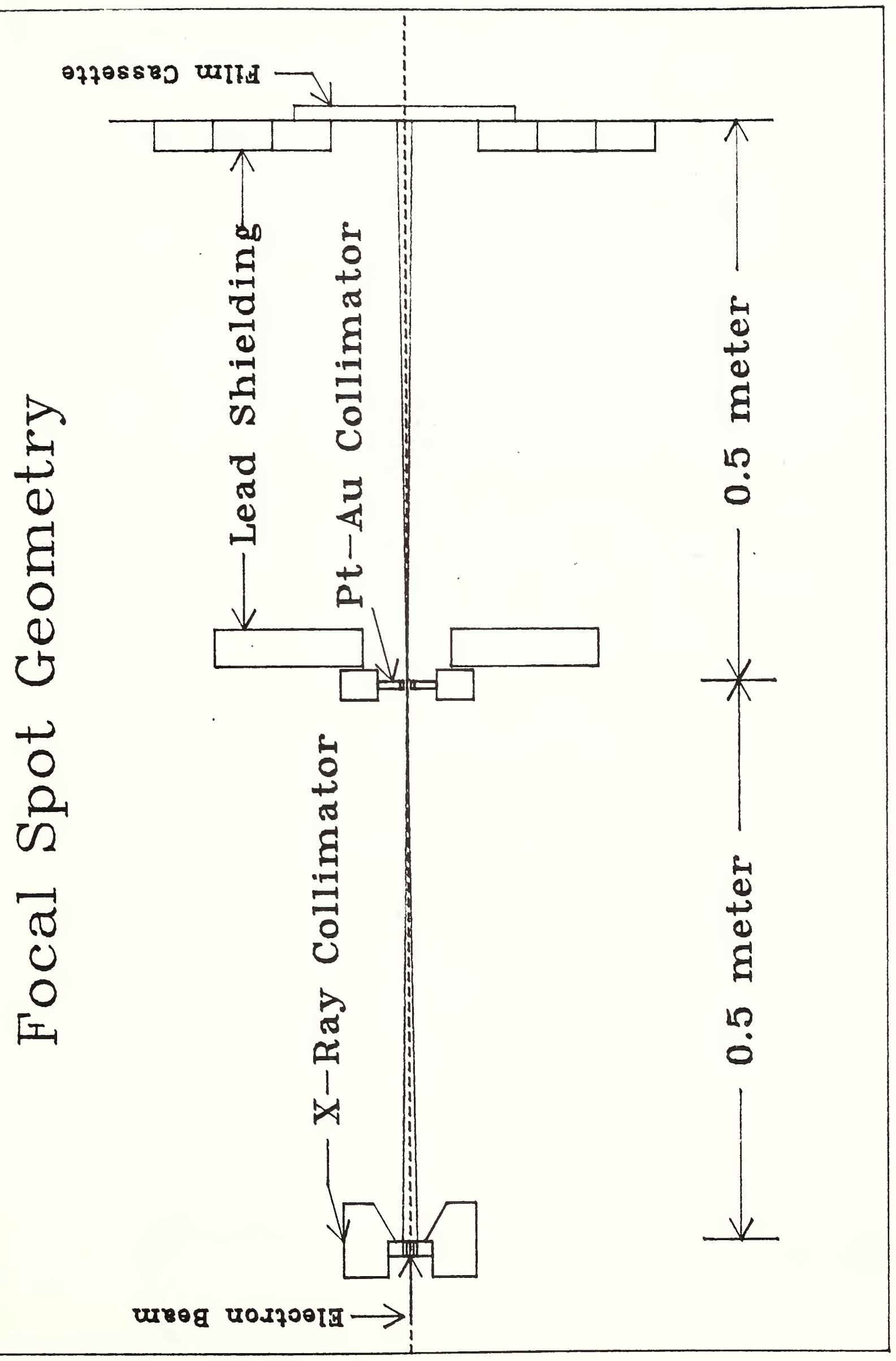


(measured from the baseline fog level) is approximately

$2.8 \times 3.1 \mathrm{~mm}$. As a further check, the measurement was repeated with a 125- $\mu \mathrm{m}$ pinhole in a $1.25 \mathrm{~cm}$ thick lead collimator placed at the same location as the Pt-Au pinhole assembly. The results of these measurements agree with the previous results to within $5 \%$

\section{THE CENTRAL AXIS RADIATION INTENSITY}

In order to measure the radiation intensity on the central axis of the accelerator, a Capintec Model 192 exposure meterl was placed on the central axis with the aid of the laser at a distance of approximately 1 meter from the $x$-ray target. This instrument which uses a 0.5-cc ionization chamber and a lucite buildup cap was calibrated in a standard ${ }^{60} \mathrm{Co}$ beam. The outside diameter of the chamber is approximately $5 \mathrm{~mm}$. In order to check the effectiveness of the buildup cap, measurements were made with the standard cap (17-mm diameter Lucite) and with other caps up to 60 mm diameter. The results of these measurements are given in Table 1 .

These data illustrate that the standard cap provides the maximum buildup for the radiation field; this cap was used for all the measurements with this chamber. Following these measurements, the ionization chamber was positioned $1+0.05$ meter from the $\mathrm{x}$-ray target. This measurement indicated that the exposure rate at this location was $1.16+0.02 \mathrm{R} / \mathrm{min}$. As indicated earlier, measurements on successive days indicated that the maximum exposure rate gradually increased from 1.16 to $1.35 \mathrm{R} / \mathrm{m}$ in. The accelerator is provided with a photosensitive diode mounted 
next to the $\mathrm{x}$-ray target to provide a relative measure of the radiation output. The readings on the current meter connected to this monitor were between 75 and 85 microamps for the outputs measured with the ionization chamber.

The readings obtained with the capintec chamber were verified with an MDH ionization chamber (MDH Model 10x5-6) 1 with a $2 \mathrm{~cm}$ diameter bakelite buildup cap. The $\mathrm{MDH}$ reading agreed with the Capintec reading to within 2\% for distances from 0.5 to 2 meters from the $\mathrm{x}$-ray target.

As a final check, the radiation field intensity was checked for inverse-square-law dependence at distances from 0.5 to 3 meters from the source. The results of these measurements are given in Table 2. These data indicate that the source very closely follows the inverse-square-law dependence for a point radiation source with an intensity of approximately 1.2 to 1.3 $\mathrm{R} / \mathrm{min}$ at 1 meter.

Table 1. Radiation intensity $(\mathrm{R} / \mathrm{min}$ at $\sim$ I meter) as measured with the capintec ionization chamber and various Lucite buildup caps.

\begin{tabular}{rcc}
\multicolumn{3}{c}{ Buildup cap } \\
Diam. (mm) & Thickness(mm) & Exposure Rate (R/min) \\
17 (standard) & 6 & 1.03 \\
38 & 16.5 & 1.02 \\
51 & 23 & 1.03 \\
60 & 27.5 & 1.05
\end{tabular}

Table 2. Inverse-square-law check of the central-axis radiation intensity with Capintec chamber.

Source to chamber distance(meter)

$\begin{array}{cc}\text { Exposure Rate } & (\mathrm{R} / \mathrm{min}) \\ \text { measured } & \text { calculated } \\ 4.61 & 4.64 \\ 1.16 & \text { assumed } 1.16 \\ 0.27 & 0.29 \\ 0.12 & 0.13\end{array}$


4. THE BEAM INTENSITY PROFILE

In order to measure the beam intensity profile, the capintec ionization chamber was mounted on an $x-y$ positioner in a plane 1 meter from the $x$-ray target. This instrument is capable of remotely positioning the ionization chamber at any point up to 10.5 inches from the central position, both horizontally and vertically, with a reproducibility of 0.002 in. In order to normalize the measurements, a large MDH chamber (Model 10X5-180)1 was centered on the beam axis approximately $30 \mathrm{~cm}$ from the x-ray target. Measurements were made with the Capintec chamber with and without the MDH chamber in place, and these data indicate that the MDH chamber used in this transmission mode did not affect the radiation intensity more than $+1 \%$ either on or off the beam axis. Using this setup, measurements of the beam intensity were taken at approximately 250 locations in this plane. These data are shown in Fig. 3 and Table 3. In Fig. 3 the exposure rate $(\mathrm{R} / \mathrm{min})$ is plotted as a function of the distance from the center of the plane. This plot indicates that the beam is nearly circular in cross section with an intensity that drops to approximately $50 \%$ of the beam axis intensity between 5 and 6 in. from the beam axis. Beyond 10 inches from the beam axis, the intensity levels out at a nearly constant background level of about $7 \%$ of the forward intensity. This is consistent with the area subtended by the $30^{\circ}$ collimator which gives a useful field of 21 in. diameter at 1 meter. In Table 3, the data are tabulated according to the actual horizontal and vertical location where they were recorded. In this table, the axis are drawn as they would be seen looking antiparallel to the $x$-ray 
Figure 3. The exposure rate in a plane 1 meter from the $x$-ray target is plotted as a function of the distance from the beam axis. These data were measured with a 0.5-cc. ionization chamber and a remote $x-y$ positioner described in the text. 


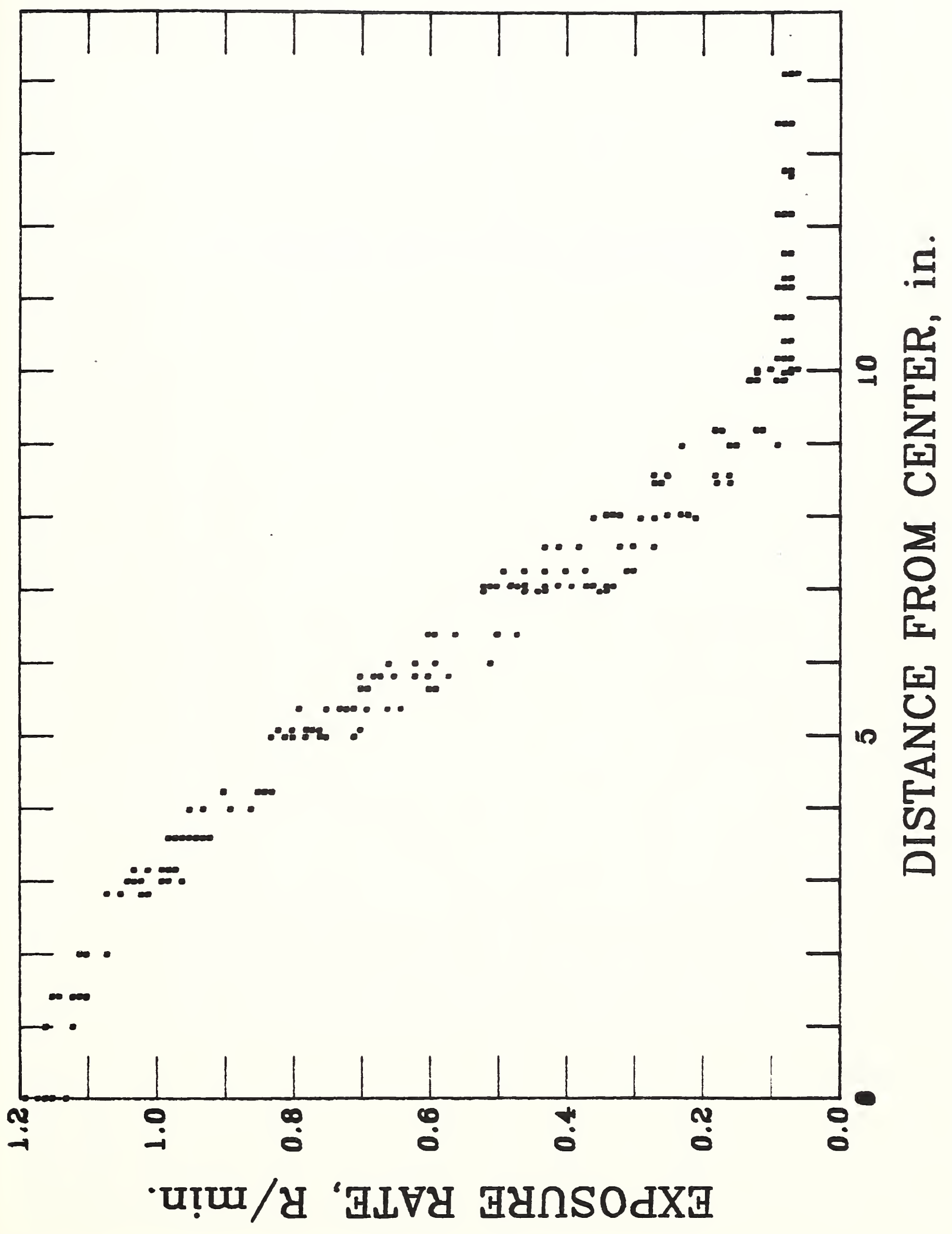


Table 3. The exposure rates plotted in Fig. 3 are tabulated according to the position in the plane where they were measured. The values given are in $\mathrm{R} / \mathrm{min}$. 


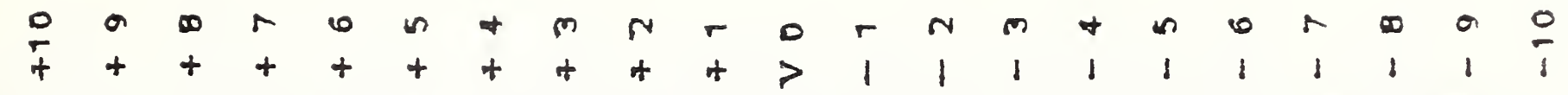

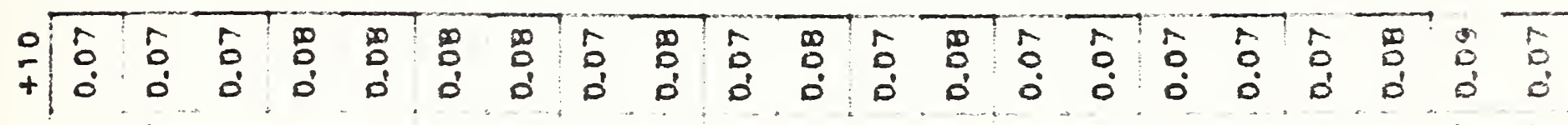

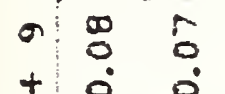

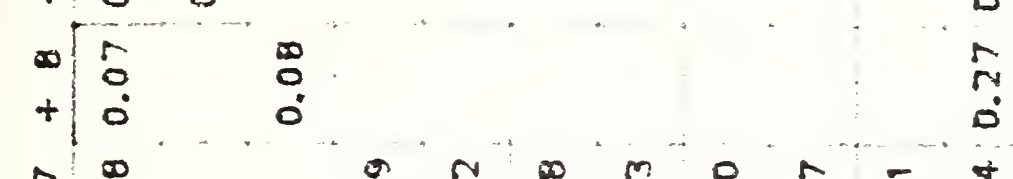
范

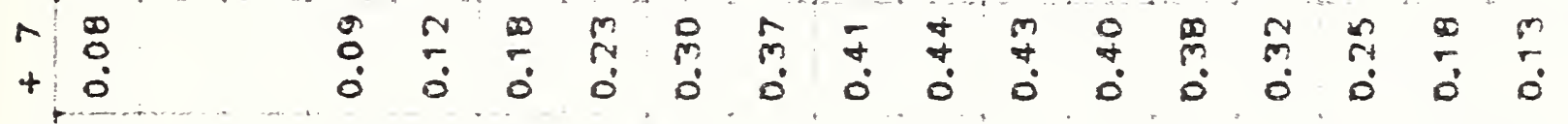

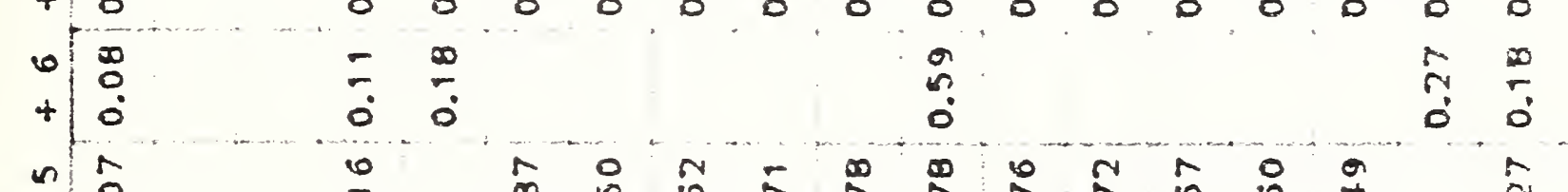

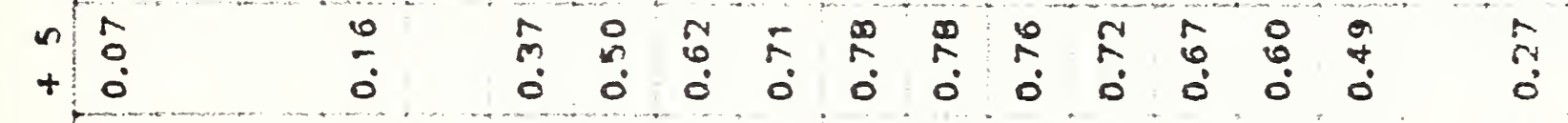

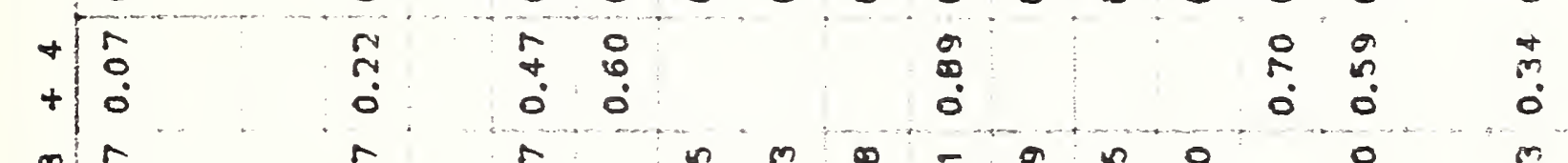

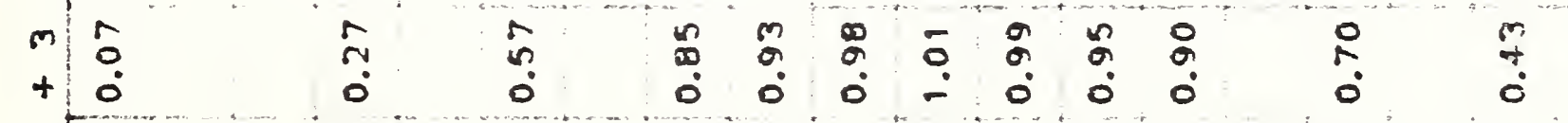

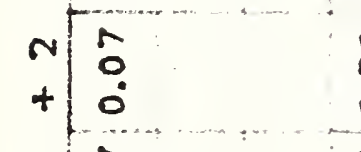

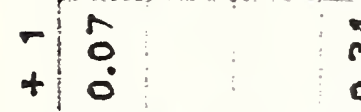

0 ०

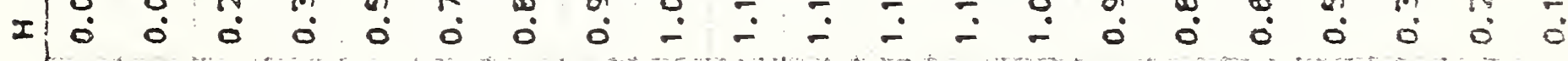

苟

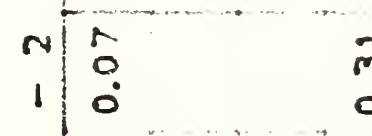

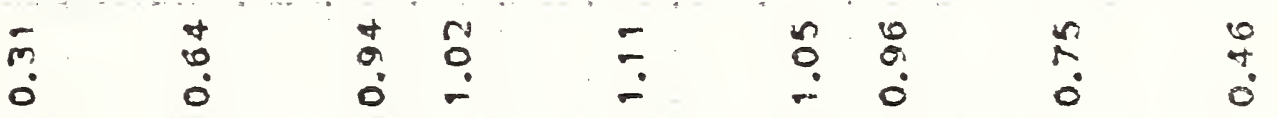

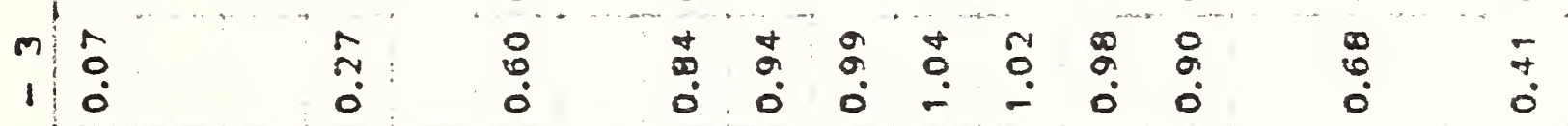

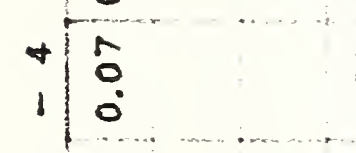

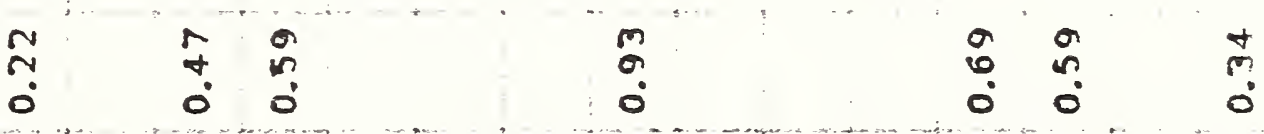

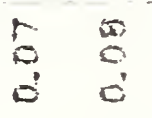

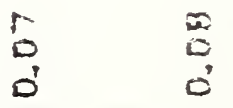

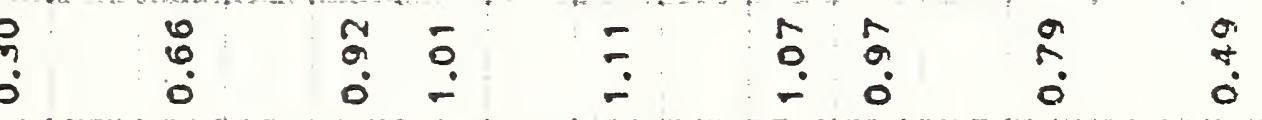

苟

๙

$1: \frac{9}{0}$

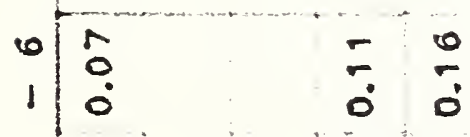

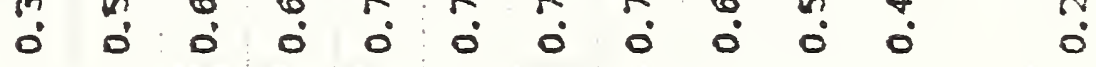

숭

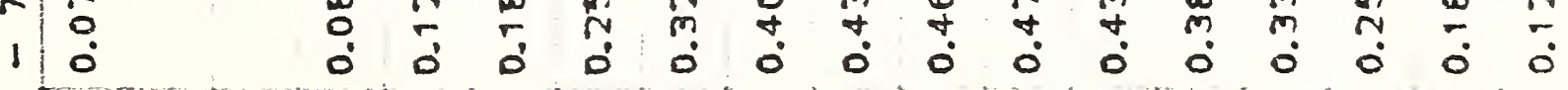

:

(2)

$\begin{array}{ll}0 & 0 \\ 0 & 0\end{array}$

$\begin{array}{lllll}5 & 5 & 0 & n \\ 0 & 0 & 0 & 0\end{array}$

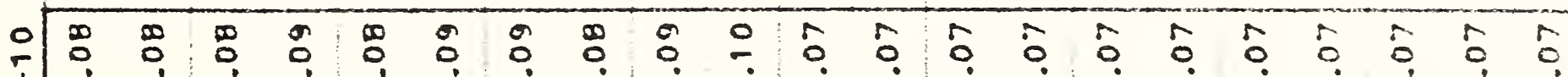

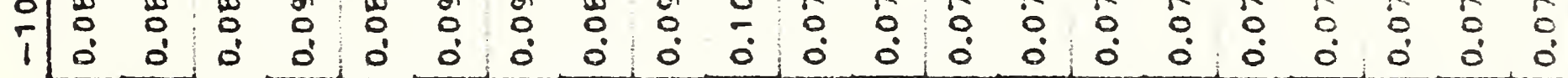


beam. These data indicate that the beam is pointed slightly down and to the right as seen from the slightly higher readings in the lower right quadrant of the table. This slight asymmetry could be compensated by a different setting of the beam steering deflection coils at the end of the accelerator. All of the data presented in the table were normalized utilizing the MDH chamber as a transmission monitor.

\section{THE X-RAY BEAM ENERGY}

In order to measure the average x-ray energy, several techniques were used. In the first method, step wedges fabricated from cold-rolled steel were placed in front of a cassette containing a $125-\mu \mathrm{m}$ thick lead front screen, Kodak Type T x-ray film l, and a $250-\mu \mathrm{m}$ thick back screen. The wedges are 2 -in. wide by 8 -in. high and have 4 steps on each wedge. These wedges were placed so as to be centered about the beam axis at a distance of 2 meters from the x-ray target. This distance was chosen to minimize the effects of the beam nonuniformity measured at 1 meter. The two step wedges have steps of 1/8-, 2/8-, 3/8-, and 4/8-in. and 0.5-, 1.0-, 1.5-, and 2.0-in., respectively. In order to monitor the exposure, the capintec and small MDH chambers were placed in contact with the rear of the cassette on either side of the step wedges. Exposures of 0.5, $1.0,2.0,4.0$, and 8.0 Roentgen were made in this geometry.

After exposure, the films were processed, and the optical density was measured in the center of each step with a densitometer. The resulting data are shown in Fig. 4. From these data, the half-value layer in steel was determined at optical 
densities of 3, 2, and 1 density units (the horizontal lines in Fig. 4). The solid lines in Fig. 4 are a computer generated quadratic fit to the data of the form:

$$
O D=a t^{2}+b t+c,
$$

where $t$ is the steel thickness in inches. Table 4 presents the values of these coefficients for the curves of Fig. 4. From these parameters the half-value layers were calculated as $0.73-, 0.64-$, and 0.64 -in of steel as shown by the vertical lines of Fig. 4.

Table 4. Coefficients for quadratic fit of step-wedge exposure data of Fig. 4 .

$\begin{array}{cccc}\text { Curve Label } & \mathrm{a} & \mathrm{b} & \mathrm{c} \\ 0.5 \mathrm{R} & 0.0566 & -0.2714 & 0.4929 \\ 1.0 \mathrm{R} & 0.1501 & -0.6093 & 0.8594 \\ 2.0 \mathrm{R} & 0.3235 & -1.3851 & 1.8172 \\ 4.0 \mathrm{R} & 0.7165 & -3.0673 & 3.8283 \\ 8.0 \mathrm{R} & 1.6344 & -6.8519 & 8.2883\end{array}$

A second method was employed to measure the half-value layer without the use of film. In this method, the Capintec smallvolume ionization chamber was placed approximately 1 meter from the $x$-ray target and 0.5 in. to one side of the beam axis. The small MDH chamber was placed 0.5 in. to the other side of the beam axis and approximately 2 in. farther from the x-ray target. Blocks of steel, brass, and aluminum measuring $2 \times 2$ in were placed between the two chambers and the Capintec chamber reading was used to normalize the MDH reading. Fig. 5 shows the results of 
Figure 4. The optical densities measured from the images of a steel step wedge are plotted as a function of the step thickness for exposures from 0.5 to $8 \mathrm{R}$. The vertical dotted lines represent the half-value layers determined from these data as described in the text. 


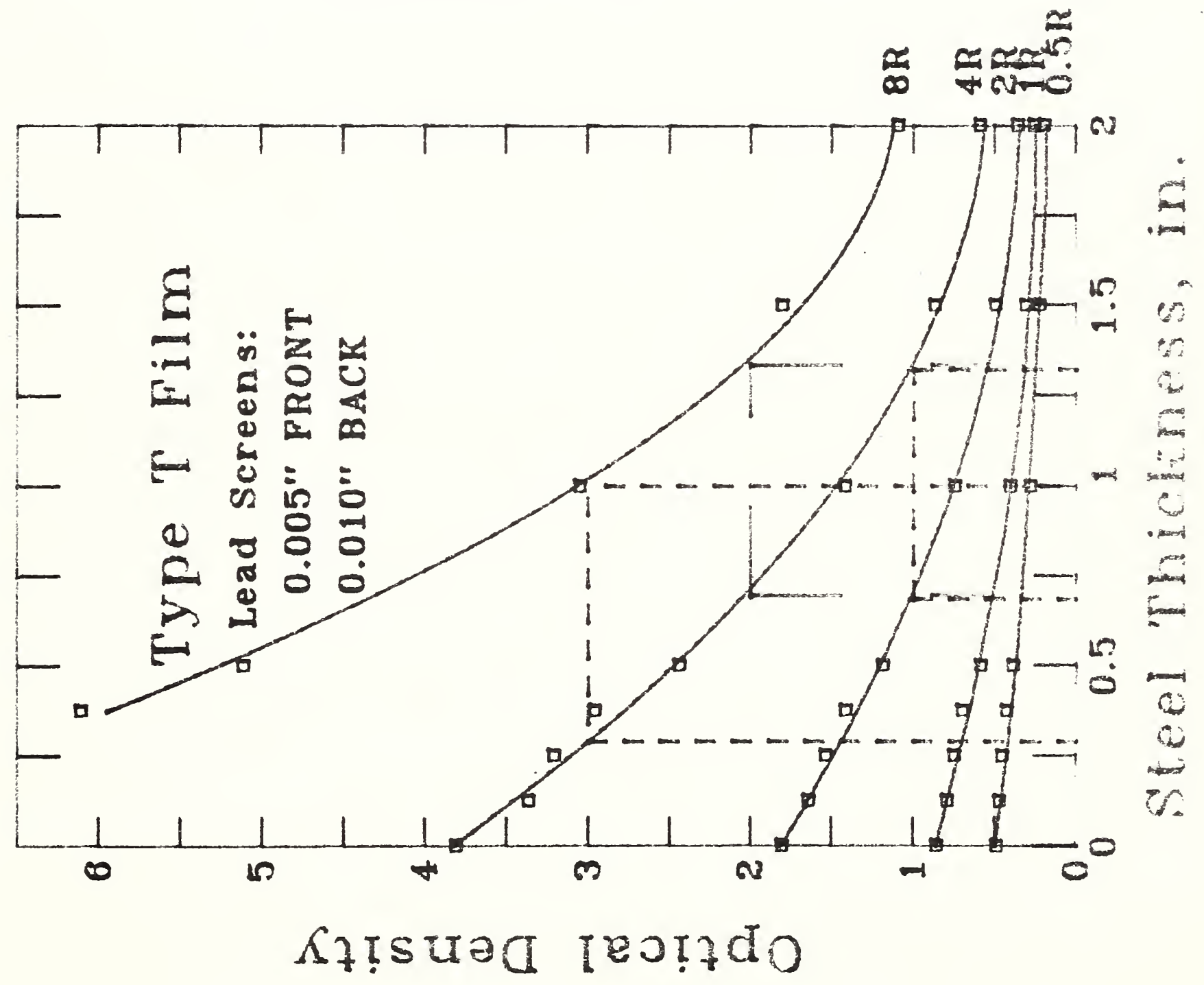


Figure 5. The exposure rates measured with a 0.5-cc ionization chamber behind step wedges of aluminum, brass, and steel are plotted as a function of the step thickness. The table gives the values of the coefficients used for the quadratic fit of the data shown by the solid lines. The horizontal dotted lines indicate $1 / 2$ and $1 / 4$ of the primary intensity respectively. 

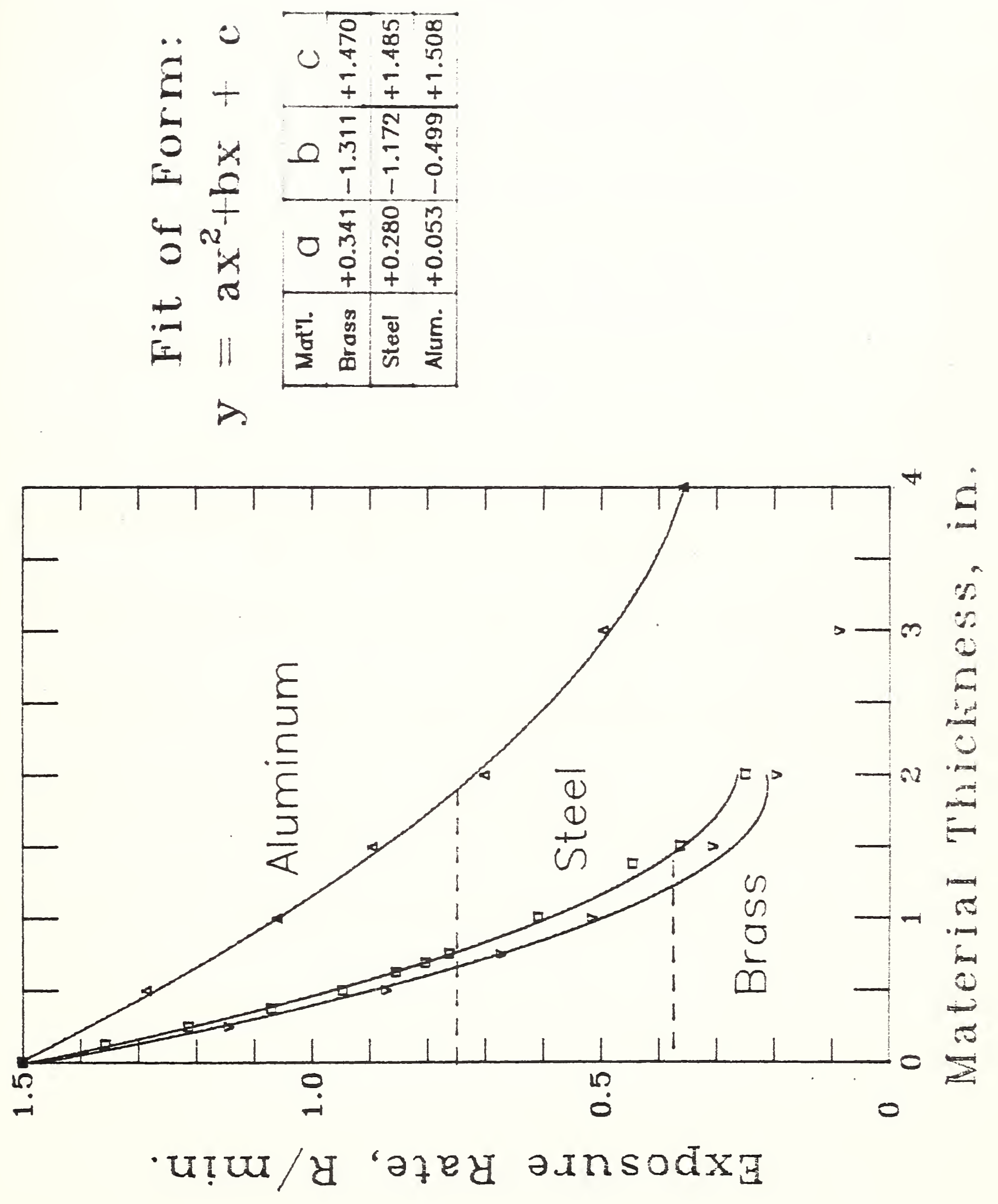
this measurement and gives the values of the coefficients generated to fit the data as before. From these data, it is possible to calculate both the first and second half-value thicknesses for these materials (the thickness of material required to reduce the exposure to one-half and one quarter). Table 5 gives these values for the three materials used.

Table 5. The first and second half-value thicknesses for the Minac x-ray beam in various materials. Material Half-value thicknesses (in.) 1st 2nd
Aluminum
1.9
1.9
Brass
0.68
0.56
Steel
0.77
0.69

These data are consistent with the values for steel as measured using the film technique described above and indicate that in steel the equilibrium half-value thickness is approximately 0.67 inches. This value corresponds to an effective x-ray energy of approximately $1 \mathrm{MeV} .4$

In order to determine the energy of the electron beam striking the $x$-ray target, an effort was made to measure the end point of the bremsstrahlung spectra utilizing an $\sim 60-c c$ highpurity germanium detector. The detector was mounted in a lead shield approximately 5 meters from the $x$-ray target and approximately 10 degrees off the beam axis. In order to reduce the counting rate in the detector, the accelerator was operated at the lowest pulse rate and with the accelerator grid control 
tuned for as low an output as possible. The beam was also heavily filtered with approximately $15 \mathrm{~cm}$ of lead between the source and the detector. The output of the detector was recorded by a pulse height analyzer and the system was calibrated with radioactive sources of ${ }^{137} \mathrm{Cs}$ and ${ }^{60} \mathrm{Co}$. Due to the pulsed nature of the radiation from the source, the measurement of the spectrum was extremely difficult and time consuming. After a 2 hour run, the data was extrapolated to determine the end point of the spectrum. The results of this extrapolation indicate that the electron energy is $1.43 \pm 0.1 \mathrm{MeV}$. This value is reasonable considering the effective energy of the photon beam of $\sim 1 \mathrm{MeV}$ determined by the half-value measurements.

\section{EXTENDED OPERATION}

In order to test the long term operation of the accelerator, it was operated continuously for a period of more than 8 hours. The output of the accelerator was monitored with an ionization chamber connected to an electrometer which was used to drive a chart recorder. For the eight hour period, there were no interruptions of the accelerator operation. For most of this period, the accelerator was operated in the manual mode. Fig. 6 shows the output of the accelerator for several periods of time. Fig. $6 a$ illustrates the output for the first 30 minutes of operation. This period is characterized by the need for periodic retuning of the magnetron frequency to maintain maximum output. The output for this period was approximately $1.3 \mathrm{R} / \mathrm{m}$ in at 1 meter. After approximately 45 minutes of running, the accelerator was quite well stabilized and needed magnetron frequency adjustment 
Figure 6. Chart recorder traces of the output of the accelerator during an extended run are shown. (a) First half-hour of operation; (b) Approximately 6 hours into run; and (c) After approximately 8.5 hours. 

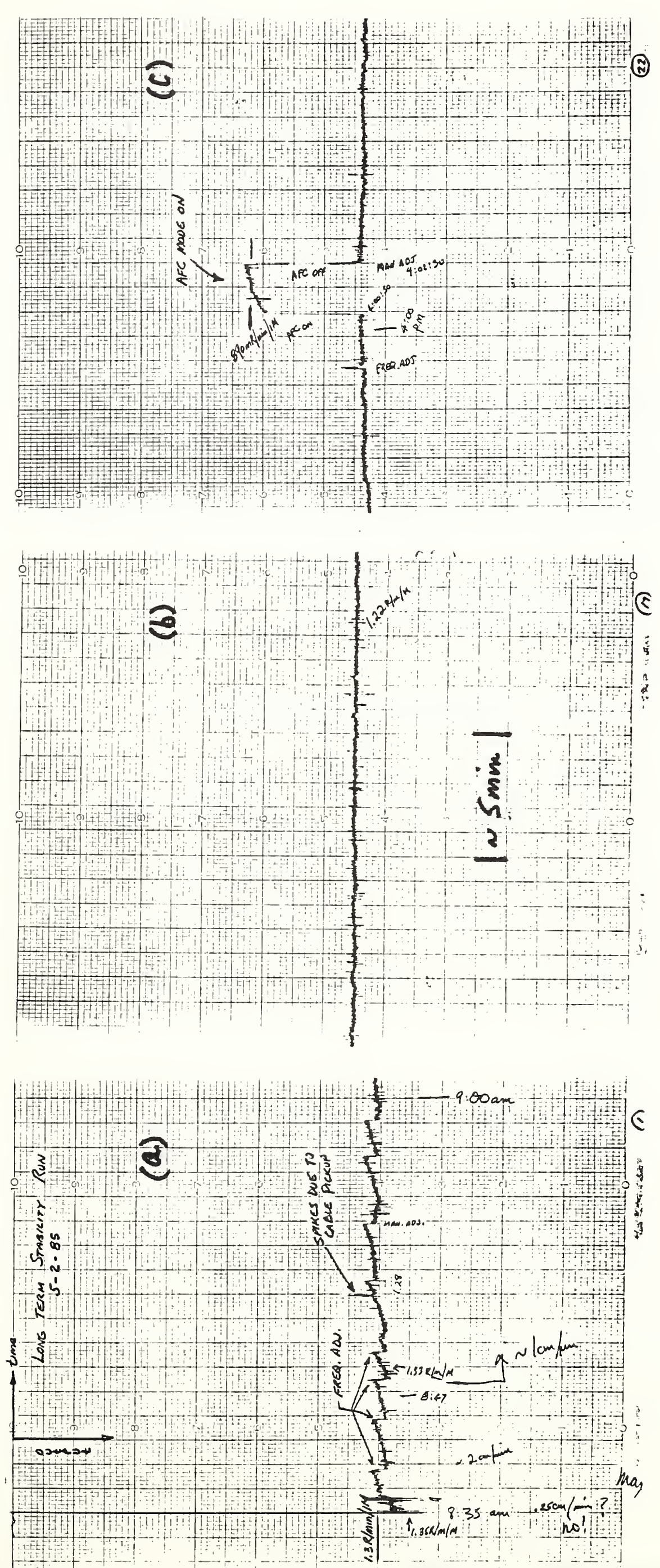
infrequently. Fig. $6 \mathrm{~b}$ illustrates the operation approximately 6 hours into the run. The output is quite stable at approximately $1.22 \mathrm{R} / \mathrm{min}$ and there were no adjustments in the $20 \mathrm{~min}$. period shown in this figure. Finally, Fig. $6 \mathrm{c}$ illustrates the operation near the end of the run and illustrates the effect of the AFC mode of operation. As can be seen from this figure, the AFC circuitry has the effect of detuning the magnetron and thus reducing the output. It may be that there is a fault in the feedback circuit used in this mode, but we made no attempt to troubleshoot this unit. However, the machine is stable enough in the manual mode so that it is quite usable for radiography.

\section{7. $\underline{X-R A Y}$ LEAKAGE}

In order to measure the $x$-ray leakage outside of the primary beam, a 2-meter diameter ring was fabricated from $1 / 8 \times 1 / 4$ in. rectangular nylon stock. This ring was positioned in three orientations relative to the accelerator with the $x$-ray source at the center. These positions were: a) Parallel to the accelerator structure (horizontal); b) Perpendicular to the accelerator structure (vertical); and c) Slanted relative to the accelerator structure with the front end of the ring below the beam line at an angle of approximately $60^{\circ}$ (slant). In order to measure the exposure, a series of thermoluminescent dosimeter (TLD) personnel badges were placed every $30^{\circ}$ around the ring. Each badge contained four TLD's with various filters as follows: two lithium borate TLD's, one with no filter (\#1) and one with a $300-\mathrm{mg} / \mathrm{cm}^{2}$ plastic filter(\#2); two calcium sulfate TLD's each with a 700$\mathrm{mg} / \mathrm{cm}^{2}$ lead filter $(\# 3 \& \# 4)$. The badges were calibrated in a 
standard ${ }^{60} \mathrm{Co}$ beam.

In order to normalize the TLD readings, the Capintec chamber was placed at 1 meter from the x-ray target on the beam axis. The TLD's were irradiated for an exposure on the Capintec of $10 \mathrm{R}$ in each of the measurements. The data for each of the three cases $(\mathrm{H}, \mathrm{V}$, and $\mathrm{S})$ are shown in the polar plots of Figs. 7-9 and given in Table 6. The data plotted in the figures is the data for TLD\#2. For the horizontal data shown in Fig. 7, the maximum leakage is about $18 \%$ of the forward intensity and is at a maximum near $90^{\circ}$. The area behind the accelerator $\mathrm{x}$-ray head is evidently shielded somewhat by the components in the structure itself. The large anomaly in the ratios of the TLD readings at $180^{\circ}$ are indicative of a softening of the spectrum as would be expected at the large angles. Note that in the tabulated values the TLD's at $0^{\circ}$ agree quite well with the integrated $10 \mathrm{R}$ exposure measured by the ionization chamber. The vertical data of Fig. 8 indicate that the leakage in this plane is fairly uniform and about 18\% of the forward intensity. The anamoly at $105^{\circ}$ is not understood. Finally, the data at a slant of $60^{\circ}$ indicate a similar behavior with a slightly higher leakage at the forward angles. These data indicate that the leakage around the accelerator is an appreciable fraction of the primary intensity and this necessitates that the operator of the instrument maintain a safe operating distance between the console location and the accelerator. A simple $1 / r^{2}$ calculation indicates that for a forward intensity of $1 \mathrm{R} / \mathrm{min}$ at 1 meter the leakage at 60 meters from the source can be as high as $0.055 \mathrm{mR} / \mathrm{min}$, with the minimum exposure rate being directly behind the accelerator. 
Figures 7-9. Polar plots of the readings of TLD Element \#2 as a percentage of the forward intensity, taken in horizontal (Fig. 7), vertical (Fig. 8), and slanted (Fig.9) planes 1 meter from the x-ray target. The data were recorded at angular intervals of $30^{\circ}$ as specified in the text. 


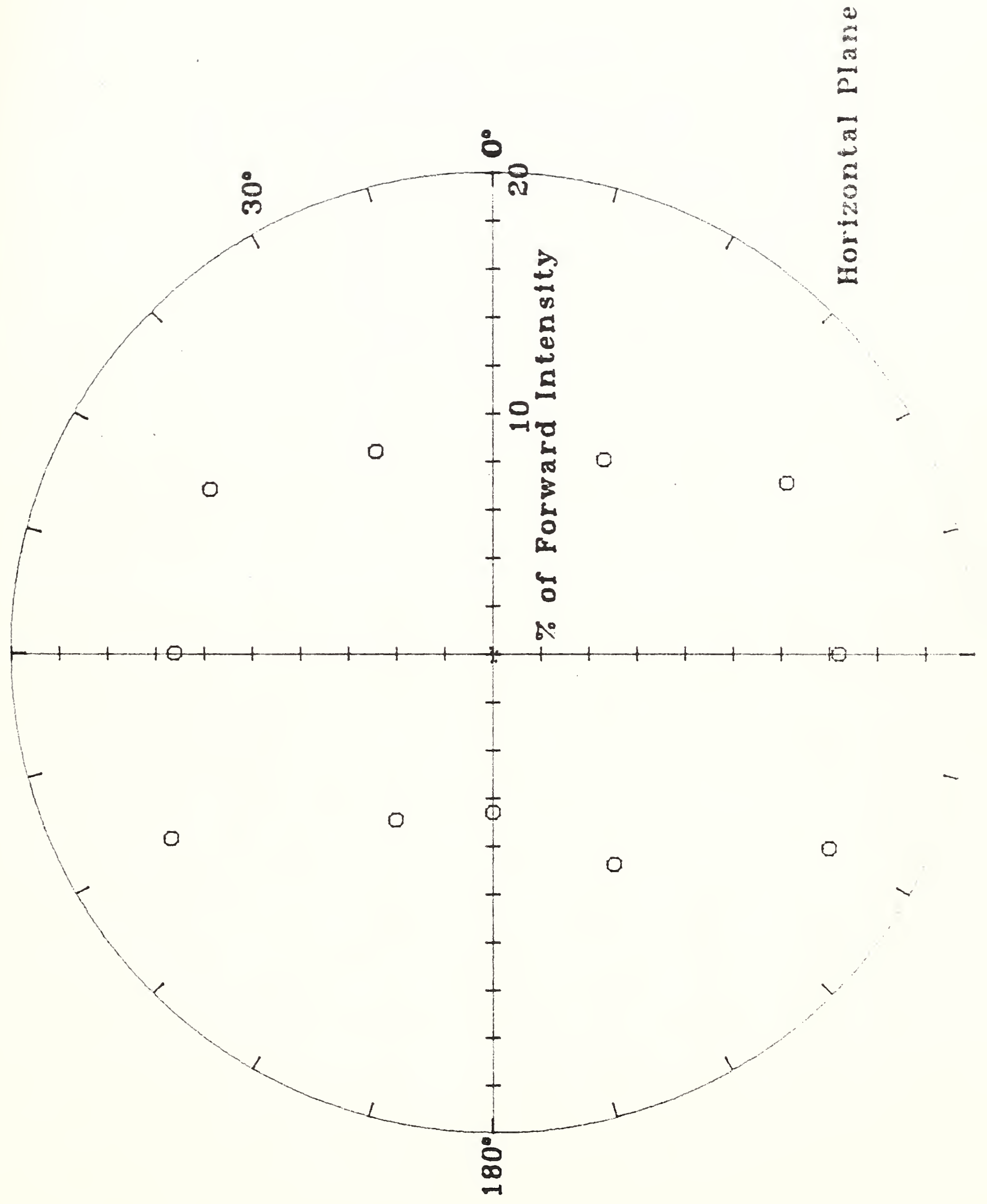




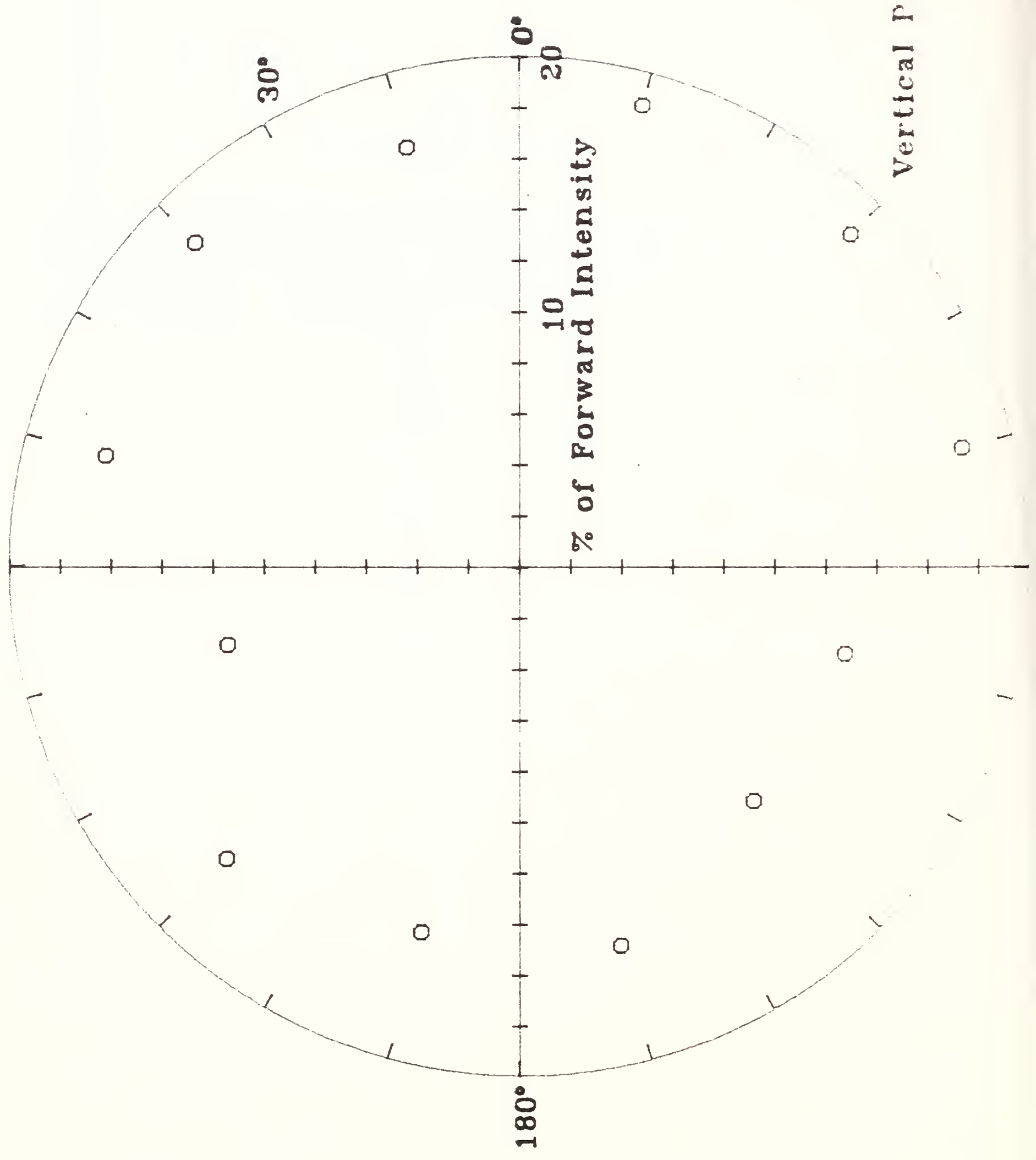




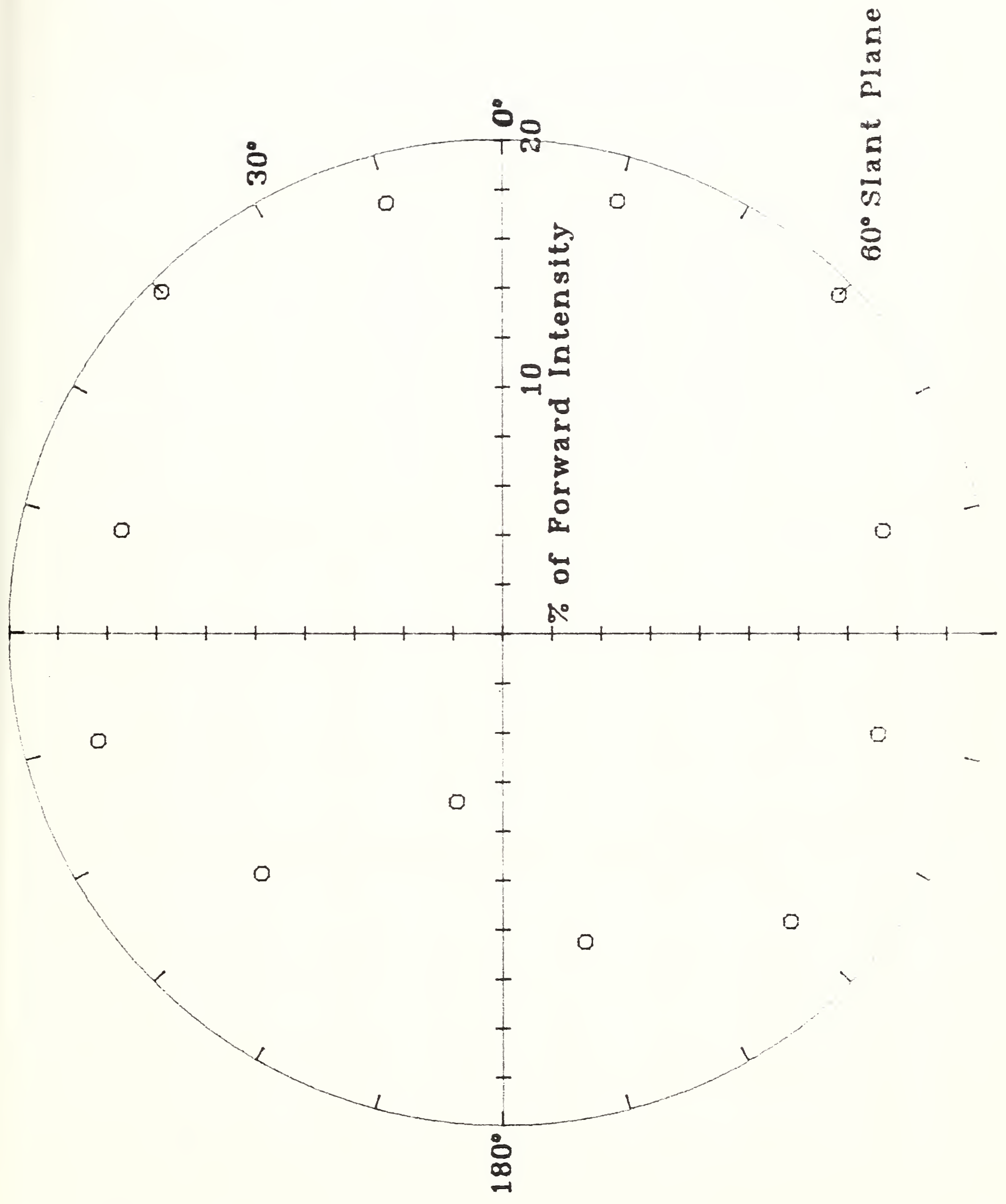


Table 6. Angular measurements of radiation leakage with TLD badges in horizontal, vertical, and slanted planes.

$\begin{array}{lcccccc}\text { ANGLE } & \text { TLD\#1 } & \text { TLD\#2 } & \text { TLD\#3 } & \text { TLD\#4 } & \text { AVG. } & \text { RATIOS } \\ \text { Deg. } & & \text { Values in } m R & & \# 3 \& \# 4 \text { \#2/\#3\&\#4 \#3/\#4 }\end{array}$

\begin{tabular}{rrrrrrrr}
\multicolumn{1}{l}{ HORIZONTAL PLANE } \\
0 & 9417.7 & 9698.4 & 10196.8 & 9939.8 & 10058.9 & 0.963 & 1.026 \\
30 & 1177.5 & 968.6 & 981.0 & 1000.2 & 990.5 & 0.978 & 0.981 \\
60 & 1656.8 & 1354.6 & 1804.9 & 1796.8 & 1801.0 & 0.752 & 1.004 \\
90 & 1511.3 & 1320.2 & 1832.1 & 1742.7 & 1789.8 & 0.739 & 1.051 \\
120 & 1892.5 & 1542.4 & 1736.7 & 1654.0 & 1697.6 & 0.910 & 1.050 \\
150 & 1607.7 & 801.1 & 1848.7 & 1809.3 & 1830.0 & 0.438 & 1.022 \\
180 & 575.7 & 660.8 & 286.5 & 218.4 & 252.4 & 2.617 & 1.312 \\
210 & 1166.3 & 1015.2 & 1063.0 & 1064.2 & 1063.6 & 0.955 & 0.999 \\
240 & 1995.1 & 1619.7 & 2127.2 & 1709.5 & 1929.1 & 0.844 & 1.244 \\
270 & 1801.8 & 1440.5 & 1900.3 & 1853.5 & 1878.1 & 0.767 & 1.025 \\
300 & 1713.9 & 1412.9 & 1907.9 & 1898.5 & 1903.4 & 0.742 & 1.005 \\
330 & 1253.1 & 927.4 & 965.3 & 982.8 & 974.0 & 0.952 & 0.982
\end{tabular}

VERTICAL PLANE

$\begin{array}{rrrrrrrr}15 & 2051.2 & 1699.2 & 2134.6 & 1733.8 & 1944.5 & 0.879 & 1.231 \\ 45 & 2010.4 & 1793.8 & 2094.3 & 2051.1 & 2073.7 & 0.865 & 1.021 \\ 75 & 2011.1 & 1675.1 & 1767.7 & 1688.2 & 1730.1 & 0.969 & 1.047 \\ 105 & 1403.2 & 1181.6 & 1232.5 & 1203.5 & 1218.1 & 0.970 & 1.024 \\ 135 & 1911.0 & 1623.9 & 1990.6 & 1942.6 & 1967.8 & 0.826 & 1.025 \\ 165 & 1893.0 & 1482.8 & 1754.1 & 1673.3 & 1715.9 & 0.865 & 1.048 \\ 195 & 1735.2 & 1537.0 & 2034.0 & 1996.6 & 2016.2 & 0.763 & 1.019 \\ 225 & 1637.7 & 1300.9 & 1845.2 & 1725.7 & 1788.6 & 0.729 & 1.069 \\ 255 & 1436.2 & 1320.9 & 1850.8 & 1467.8 & 1847.2 & 0.796 & 1.261 \\ 285 & 2069.4 & 1796.4 & 2124.6 & 2077.7 & 2102.3 & 0.855 & 1.023 \\ 315 & 2138.3 & 1836.9 & 2251.2 & 2220.5 & 2236.6 & 0.822 & 1.014 \\ 345 & 2104.9 & 1867.0 & 1869.6 & 1826.8 & 1849.3 & 1.010 & 1.023 \\ & & & & & & & \\ 600 & \text { SLANT PLANE } & & & & & & \\ 15 & 2042.3 & 1801.2 & 2181.5 & 2109.9 & 2147.4 & 0.839 & 1.034 \\ 45 & 2380.4 & 1943.6 & 1954.4 & 2260.9 & 2100.3 & 0.922 & 0.864 \\ 75 & 1877.6 & 1592.8 & 2010.5 & 1935.9 & 1975.0 & 0.807 & 1.039 \\ 105 & 1880.4 & 1694.8 & 2049.8 & 2002.5 & 2027.3 & 0.836 & 1.024 \\ 135 & 1582.3 & 1381.1 & 1399.6 & 1378.0 & 1388.9 & 0.994 & 1.016 \\ 165 & 1060.5 & 709.2 & 782.9 & 707.1 & 745.2 & 0.952 & 1.107 \\ 195 & 1573.8 & 1298.0 & 1314.7 & 1320.1 & 1314.4 & 0.985 & 0.996 \\ 225 & 1923.0 & 1653.7 & 2102.3 & 2034.8 & 2070.1 & 0.799 & 1.033 \\ 255 & 2080.1 & 1579.1 & 2117.9 & 2032.1 & 2077.1 & 0.761 & 1.042 \\ 285 & 1918.0 & 1599.8 & 2027.9 & 1927.6 & 1980.2 & 0.890 & 1.052 \\ 315 & 2210.2 & 1932.5 & 1977.0 & 1936.8 & 1957.9 & 0.988 & 1.021 \\ 345 & 2056.3 & 1811.1 & 2147.7 & 2048.0 & 2100.2 & 0.863 & 1.049\end{array}$


8. CALCULATION OE THE X-RAY SPECTRUM

As indicated in Section 5, knowledge of the x-ray energy spectrum is largely inaccessible by direct measurement because of the well-known failure of most spectrometers to count in such a high-flux radiation field. In order to develop spectral information, Monte Carlo calculations were performed using the electron/photon transport code ZTRAN5,6, a variant of the wellestablished Monte Carlo code ETRAN $7-12$.

The Monte Carlo method treats in detail the complex process of bremsstrahlung production as the incident electrons slow down and change direction in the target, and the scattering and absorption of the emitted photons prior to escape from the target. Electron energy loss (including fluctuations), due to ionization and excitation events and due to bremsstrahlung emission, is accounted for throughout the electron histories; angular deflections from elastic and inelastic collisions are sampled along the electron trajectories. The photon histories are traced by sampling successive photon interactions in direct analogy to the physical process (Compton scattering, photoelectric absorption, and pair production).

The calculation takes into account all secondary radiations, including knock-on electrons from electron-impact ionization effects, bremsstrahlung and characteristic x rays, Compton electrons, photoelectrons, electron-positron pairs, and annihilation radiation. All generations of electrons and photons in the target with energies above chosen cut-off values are followed. A weighting scheme allows for the sampling of bremsstrahlung photon histories in excess of the natural 
production rates so that statistical fluctuations in the bremsstrahlung results can be reduced without an increase in the time-consuming number of electron histories. The statistical accuracy of the photon results is also improved by scoring for each collision point in the photon history the probability that the photon crosses the boundaries of interest without further interaction (collision-density method) .

The code makes use of a large body of electron and photon cross section data. The present calculations incorporate the latest information on electron stopping powers 13,14 and bremsstrahlung cross sections 15 and on photon interaction probabilities 16 .

The distribution of emergent bremsstrahlung photons was calculated for 1.5-MeV electrons normally incident on a tungsten target $1.618 \mathrm{~g} / \mathrm{cm}^{2}$ (0.033 in.) thick and assumed to be laterally unbounded (semi-infinite slab). The tungsten layer was followed by a $0.1205 \mathrm{~g} / \mathrm{cm}^{2}$ thick air layer to account for the slight attenuation by 1 meter of air. The results are based on the simulation of 40,000 incident electron histories and of 1.2 million emitted bremsstrahlung photon histories. All generations of electrons and photons were followed until they escaped from the target or reached a cut-off energy of $100 \mathrm{keV}$.

of interest in the present application is the fluence spectrum of photons transmitted in a small cone about the beam axis. The results indicate that there is only a small variation in the shape of the transmitted photon spectra with the angle of emergence. Therefore, the results integrated over emergent angles from 0 to 30 degrees to improve statistical accuracy are 
used to represent the spectrum at 00 . The resultant energyweighted (intensity) spectrum ES(E) is shown in Fig. 10 and tabulated in Table 7. The intensity spectrum has been arbitrarily normalized to unit area (with energy in MeV). The corresponding number spectrum $S(E)$, obtained by dividing the intensity spectrum in Fig. 10 or Table 7 by photon energy, has an area of 2.05 with the present normalization.

Table 7. Energy-weighted intensity spectrum, ES(E) of $x$ rays transmitted by $0.033-i n . ~ W(+1 \mathrm{~m}$ air) bombarded by $1.5 \mathrm{MeV}$ electrons. Results are from Monte Carlo calculations.

Photon Energy

$\mathrm{E}(\mathrm{MeV})$

0.100

0.125

0.150

0.175

0.200

0.250

0.300

0.350

0.400

0.450

0.500

0.550

0.600

0.700

0.800

0.900

1.000

1.100

1.200

1.300

1.400

1.500
Intensity spectrum

$\mathrm{ES}(\mathrm{E})$

0.000

0.078

0.269

0.490

0.758

1.180

1.298

1.343

1.328

1.270

1.201

1.129

1.058

0.913

0.785

0.672

0.572

0.482

0.390

0.296

0.129

0.000

In order to check the calculated $\mathrm{x}$-ray spectrum against measured quantities, the exposure from the calculated beam to a small ionization chamber behind iron plates was estimated. Considering only simple attenuation, the dose behind a iron slab 
Figure 10. The calculated intensity spectrum ES(E) for the Minac 1500 linac. The corresponding number spectrum $S(E)$ may be obtained by dividing by the photon energy. 


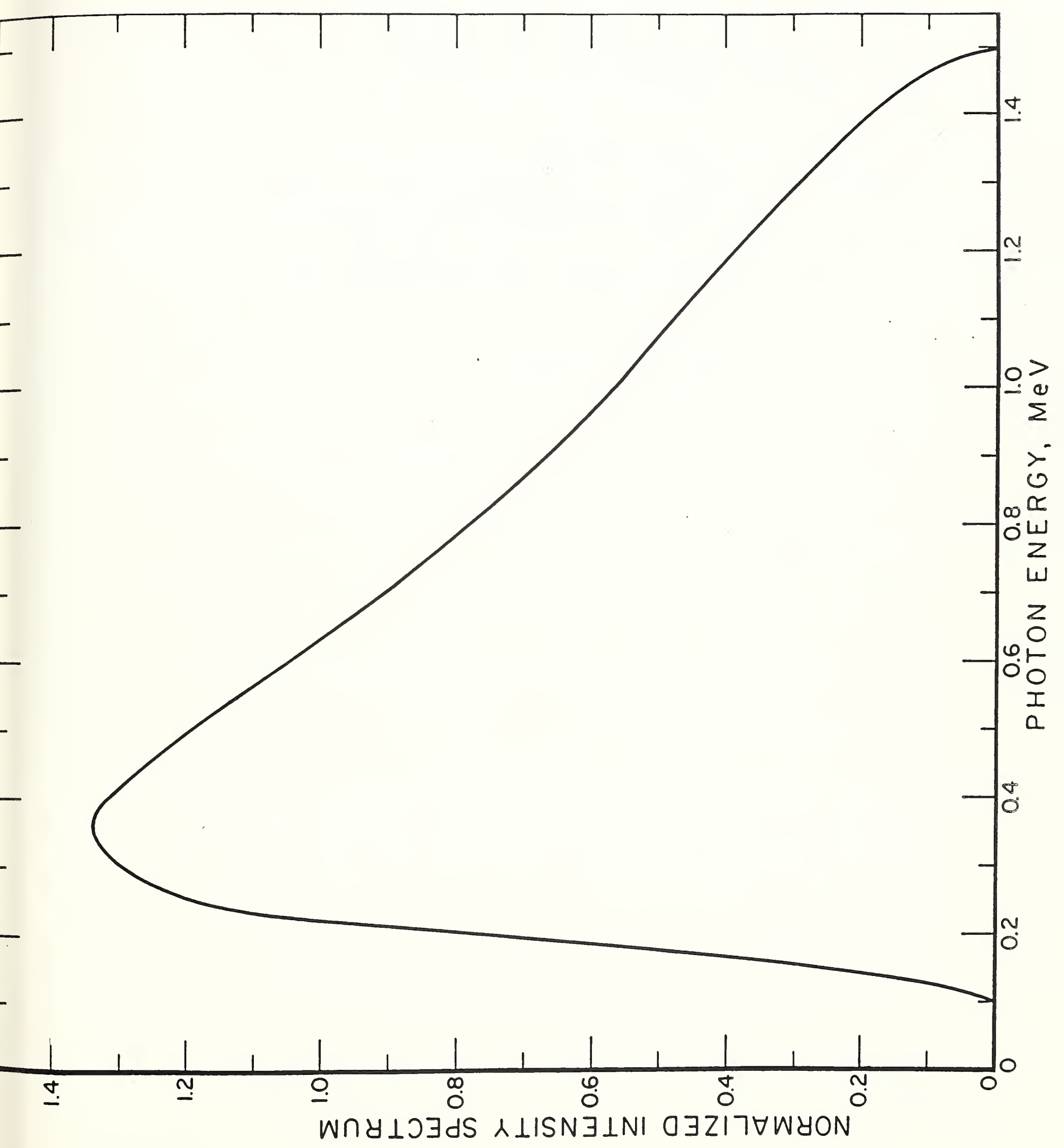


of thickness $t$ is:

$$
D_{0}(t)=\int d E E \mu \frac{\operatorname{air}}{\operatorname{en}}(E) S(E) e^{-\mu(E) t,}
$$

where $S(E)$ is the incident energy spectrum, $\mu$ eirn $(E)$ is the mass energy-absorption coefficient for air, and $\mu(E)$ is the narrowbeam attenuation coefficient for iron Eq. 2 ignores the contribution from photons scattered in the iron absorber, and therefore gives the dose to a point detector from an extremely thin pencil beam.

In order to include the dose from scattered photons, Monte Carlo calculations were done for the x-ray spectrum $S(E)$ normally incident on iron slabs with thicknesses $t=13,20$, and $40 \mathrm{~g} / \mathrm{cm}^{2}$. In each case the scattered photon fluence $E_{S}(E, t)$ in a small air volume was calculated for a broad beam, based on a sample of 0.5 million photon histories. The dose contributed by scattered photons is given by

$$
D_{S}(t)=\int d E E \mu \operatorname{ein}^{\operatorname{air}}(E) F_{S}(E, t) \text {. }
$$

Table 8 gives the ratio $B(t)=D_{S}(t) / D_{O}(t)$, or the build-up factor so obtained.

Table 8. Dose build-up factors for transmission through iron slabs. Results pertain to a normally incident broad beam of photons with the calculated spectral distribution given in Table 7 and Fig. 11

$\begin{array}{llccc}\text { Iron Thickness }\left(\mathrm{g} / \mathrm{cm}^{2}\right): & 0 & 13 & 20 & 40 \\ \text { Build-up factor: } & 0 & 0.739 & 1.08 & 2.06\end{array}$

Dose transmission curves are plotted in Fig. 11, based on $D_{0}(t)$ only (narrow beam) and on $D_{O}(t)$ plus $D_{S}(T)$ (broad beam). The 
Figure 11. Calculated curves of dose transmission through iron plates, for narrow- and broad-beam geometries. The data points are the measured values from section 6. 


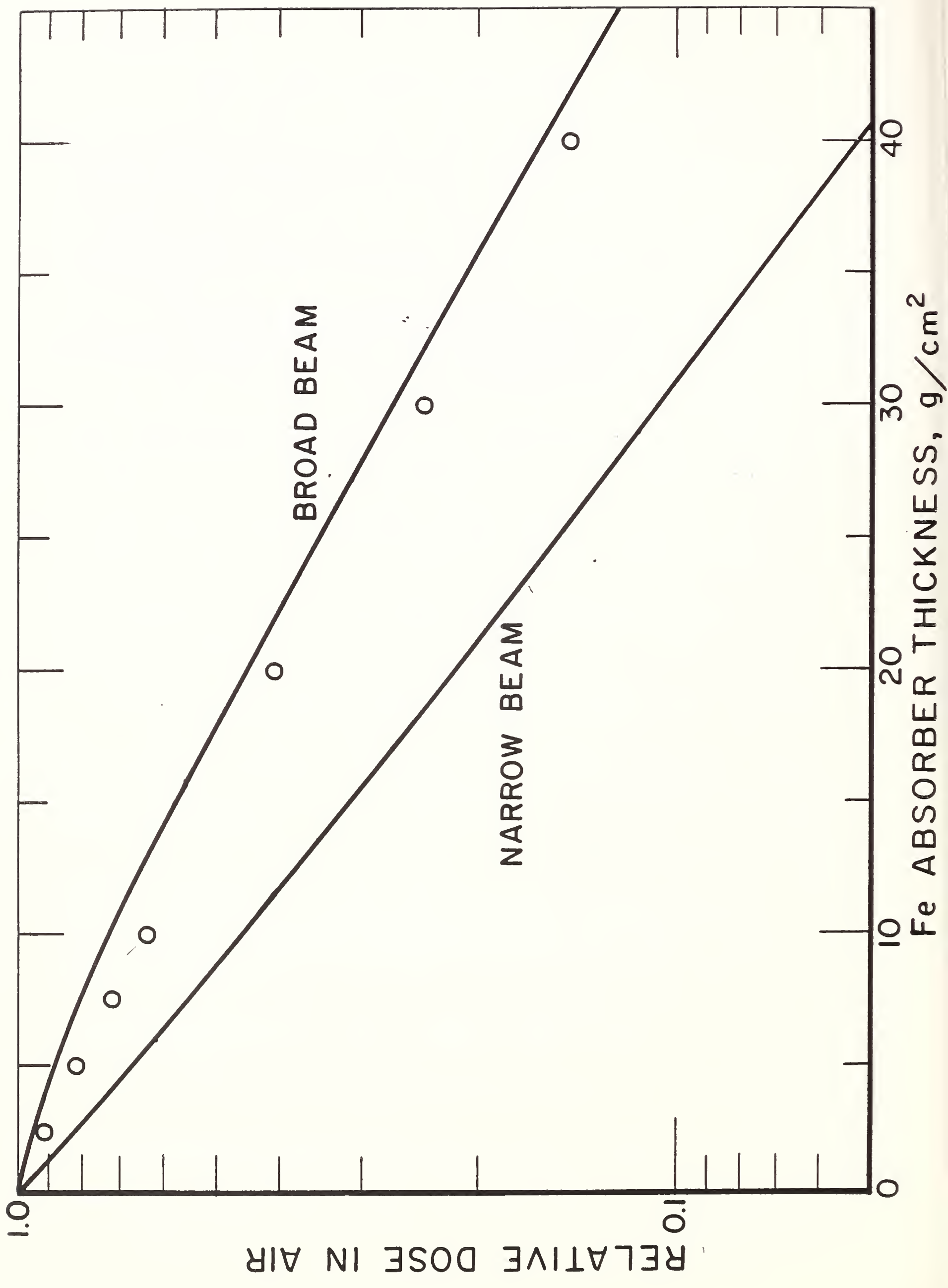


measured transmission data for the steel step wedges (Fig. 5) are plotted as points in Fig. 11. The actual measurement geometry is intermediate to narrow- and broad-beam conditions, being closer to broad beam geometry (with an effective beam radius corresponding to $1-3$ mean free paths of the incident $x$ rays). The first and second half-value thickness from the calculated results are compared to measured values in Table 9. The reasonably good agreement is sufficient to confirm consistency between calculated and measured results, and to obviate further photon transmission calculations in more complicated geometry.

Table 9. Comparison of measured and calculated half-value thickness for the Minac x-ray beam in steel plates.

$$
\begin{gathered}
\text { Half-value Thickness }\left(\mathrm{g} / \mathrm{cm}^{2}\right) \\
\text { Measureda }
\end{gathered}
$$

$\begin{array}{lll}1^{\text {st }} & 15.4 & 17.7 \\ 2^{\text {nd }} & 13.8 & 13.8\end{array}$

a Based on a density of $7.874 \mathrm{~g} / \mathrm{cm}^{3}$

\section{TRIAL RADIOGRAPHS}

In order to assess the usefulness of the linac for radiography, several trial radiographs were made. The first radiograph was of an electronic amplifier enclosed within a nuclear instrument module (NIM). This instrument is contained on one printed circuit board within a l-in. thick module with 0.062 in. aluminum sides. The amplifier module was placed 2 meters from the $\mathrm{x}$-ray target in contact with the $\mathrm{x}$-ray film cassette. The film cassette was loaded with type $\mathrm{T}$ film and the same lead 
intensifying screens used previously (125- $\mu \mathrm{m}$ front and $250-\mu \mathrm{m}$ back). The small MDH ionization chamber was placed behind the amplifier, and the film was exposed for an integrated exposure of 2R.

Examination of the resulting radiograph shows the excellent detail that is present. The printed circuit traces consisting of 50- $\mu m$ of silver on a 1-mm thick glass epoxy substrate are visible. Other objects with higher contrast such as the tantalum capacitors and the potentiometers are clearly imaged. In particular, the leads on a TO-5 transistor can are clearly visible as is the orientation tab.

In order to make an estimate of the detectability available, the steel step wedges used in the determination of the half-value layer were set up at the 2 meter location. A variety of penetrameters were placed in front of the step wedges, and a double-loaded film cassette was placed behind the assembly. The film cassette contained a $125-\mu \mathrm{m}$ lead front screen, Kodak type M film, a 125- $\mu \mathrm{m}$ tantalum screen, Kodak type $\mathrm{T}$ film, and a $250-\mu \mathrm{m}$ lead back screen. The penetrameters placed in front of the various steps of the steel wedge are listed in Table 10. In this table, the penetrameters labeled with the \# sign are steel sheets with thicknesses in mils ( $1 \mathrm{mil}=0.001$ in.) equal to the number of the penetrameter (i.e. \#5 is 0.005 in. thick). In addition, each of these penetrameters has a $0.010-, 0.020-$, and a 0.040 in. drilled hole. The penetrameters labeled 1-ISO-7 and 6-ISO-12 are wire penetrameters, each containing 7 steel wires. The 1ISO-7 penetrameter has wires of 3.2-, 2.5-, 2.0-, 1.6-, 1.25-, 1.0-, and 0.8-mm diameter while for the 6-ISO-12 penetrameter, 
the wire diameters are $1.0-, 0.8-, 0.63-, 0.5-, 0.4-, 0.32-$, and 0.25-mm. The small MDH ionization chamber was centered behind the 1-and 1.5-inch steps, and the film was exposed until the MDH ionization chamber indicated a reading of $2 \mathrm{R}$.

Table 10. Penetrameters placed in front of the steel step wedges. Step Thickness (in.) Penetrameter
0.125
Lead letters 'PEN' (no penetrameter)
0.250
\#5 (0.005 in.) \& \#10 (0.010 in.)
$0.375 \& 0.500$
1-ISO-7 wire penetrameter
0.500
\#10 (0.010 in.) \&\#20 (0.020 in.)
1.000
$\# 20(0.020$ in.)

$1.500 \& 2.000$

6-ISO-12 wire penetrameter

After processing, the radiographs were visually inspected by a trained observer to determine the detectability of the various. penetrameters. The results of these observations are given in Table 11 along with the optical densities measured behind each step of the wedges. The results of these observations indicate that there is a wide latitude of sensitivity available to the radiographer with the appropriate choice of $x$-ray film, and that $2 \%$ contrast differences (0.020 in./ 1 in.) can readily be detected. 
Table 11. Detectability of various contrast differences from the penetrameter images tabulated in Table 10. The values in the table are the minimum sizes detectable. Percent values refer to the steel sheets, i.e. $2 \%$ in $2 / 8$ in. indicates that the \# 5 penetrameter is visible on the $1 / 4$ in. step.

$\begin{array}{cccc}t & \text { M film } & \text { T film } \\ \text { (in.) OD } & \text { Detectability } & \text { OD } & \text { Detectability }\end{array}$

$1 / 8 \quad 1.62 \quad 4.23$

$2 / 8 \quad 1.562 \%$ contrast, .04" hole $4.052 \%$ contrast, $.04 "$ hole

3/8 1.416 wires, $.32 \mathrm{~mm}$. dia. 3.637 wires, $.25 \mathrm{~mm}$. dia.

4/8 1.255 wires, .40 mm. dia. 3.146 wires, $.32 \mathrm{~mm}$. dia.

$0.51 .292 \%$ contrast, .02" hole $3.302 \%$ contrast, $.02 "$ hole

$1.00 .852 \%$ contrast, .04" hole $2.012 \%$ contrast, .04" hole

1.50 .566 wires, $1.0 \mathrm{~mm}$. dia. 1.18 .7 wires, $0.8 \mathrm{~mm}$. dia.

2.00 .395 wires, $1.25 \mathrm{~mm}$. dia. 0.736 wires, $1.0 \mathrm{~mm}$. dia. 
10. SUMMARY

We have outlined a series of measurements and calculations that were made to characterize a radiation source designed for radiographic applications. For this particular source, the pertinent parameters are summarized as follows:

- Eocal Spot Size $3 \mathrm{~mm}$.

- Half-value Layer 0.69 in. steel

- Electron Energy $\quad 1.5 \mathrm{MeV}$

- Off axis leakage $18 \%$

- Output $1.2 \mathrm{R} / \mathrm{min}$ at 1 meter

From these data, a radiographer can select the operating parameters necessary for the completion of a particular radiographic task and utilize the source in a safe and efficient manner.

\section{ACKNOWLEDGEMENTS}

The authors would like to acknowledge the assistance of JuIian Sparrow in the $x-y$ position measurements. We are also grateful to Martin Ganoczy for the use of the scanningmicrodensitometer used to detemine the focal spot size. 


\section{REEERENCES}

1. Throughout this report certain commercial products are mentioned by name. This identification is for informational purposes only to specify experimental procedure. This does not imply that the products mentioned are necessarily the best or the only ones available for the purpose or imply endorsement by the National Bureau of Standards.

2. R.G. Schonberg, R.H. Miller, J.N. Weaver, W. Johnson, W.R. Fowkes, and H. Deruyter, Bull. Am. Phys. Soc. 30, 926 (1985).

3. Unless otherwise specified, all film was processed at $68{ }^{\circ}$ for $8 \mathrm{~min}$. in Kodak GBX developer followed by $30 \mathrm{sec}$. in the stop bath and $8 \mathrm{~min}$. in Kodak GBX fixer.

4. See for example; R. Halmshaw, The Physics of industrial Radiography, Elsevier Publishing Co., New York, (1966), pp 134-141.

5. S. M. Seltzer and M.J. Berger, NBSIR 84-2931 (1984).

6. S.M. Seltzer, J.P. Farrell, and J. Silverman, IEEE Trans. Nucl. Sci. NS-30, 1629 (1983).

7. M.J. Berger, Methods in Computational Physics (eds. B. Adler, S. Fernbach, and M. Rotenberg) Vol. 1, Academic Press, New York (1983).

8. M.J. Berger and S. M. Seltzer, NBS Reports 9836 and 9837 (1968); also available as Report CCC-107/ETRAN, Radiation Shielaing Information Center, Oak Ridge National Laboratory.

9. M.J. Berger and S.M. Seltzer, Phys. Rev.C2, 621 (1970).

10. S.M. Seltzer, NBSIR 74-457 (1974) .

11. S.M. Seltzer and M.J. Berger, Nucl. Instr. and Meth.119, 157 (1974).

12. S. M. Seltzer and M.J. Berger, NBSIR 78-1534 (1978).

13. S.M. Seltzer and M.J. Berger, Int. J. Appl. Radiat. Isot. 33 1189 (1982); ibid. 33, 1219 (1982); ibid 35, 665 (1984).

14. M.J. Berger and S.M. Seltzer, NBSIR 82-2550-A (1983); M.J. Berger, H.H. Andersen, H. Bichsel, J.A. Dennis, M. Inokuti, D. Powers, S.M. Seltzer, and J.E. Turner, ICRU Report 37 (1984).

15. S.M. Seltzer and M.J. Berger, Nucl. Instr. Meth. B, in press; IEEE Trans. Nucl. Sci. NS-30, 4368 (1983). 
16. J. H. Hubbell, Int. J. Appl. Radiat. Isot. 33,1269 (1982) . 
NBS.114A (REV. 2-8C)

U.S. DEPT. OF COMM.

BIBLIOGRAPHIC DATA

SHEET (See instructions)

1. PUBLICATION OR

REPORT NO.

NBSIR 85-3209

2. Performing Organ. Report Nof 3. Publication Date

AUGUST 1985

4. TITLE AND SUBTITLE

Radiation Measurements on a Portable 1.5-MeV Electron Linac

5. $A \cup T H O R(S)$

C.E. Dick, D. Polansky, C.G. Soares and S.M. Seltzer

6. PERFORMING ORGANIZATION (If joint or other than NBS, see instructions)

7. Contract/Grant No.

NATIONAL BUREAU OF STANDARDS

DEPARTMENT OF COMMERCE

WASHINGTON, D.C. 20234

9. SPONSORING ORGANIZATION NAME AND COMPLETE ADDRESS (Street, City. State, ZIP)

8. Type of Report \& Period Coverec

10. SUPPLEMENTARY NOTES

Document describes a computer program; SF-185, FIPS Software Summary, is attached.

11. ABSTRACT (A 200-word or less foctual summary of most significant information. If document includes a significant bibliography or literature survey. mention it here)

We have carried out an exhaustive series of measurements on the properties of a $1.5 \mathrm{MeV}$ electron linac designed for radiographic applications. Measurements of the focal spot size, central axis radiation intensity, radiation field uniformity, beam penetration, and radiation leakage have been made to characterize the source. Additionally, Monte Carlo calculations of the source output have been made to determine if the geometry is amenable to a theoretical analysis. Although these data pertain to a particular radiation source, the techniques described are applicable to the characterization of a large class of radiation producing devices.

12. KEY WORDS (Six to twelve entries: alphabetical order: capitalize only proper names; and separate key words ty semicolons) Electron linac, radiography, foral spot, radiation intensity, Monte Carlo calculations.

13. AVAILABILITY

X] Unlimited

For Official Distribution. Do Not Release to NTIS

Order From Superintendent of Documents, U.S. Government Printing Office, Washington, D.C. 20402.

14. NO. OF

PRINTED PAGES

50

15. Price

$\$ 8.50$

X Order From National Technical Information Service (NTIS), Springfield, VA. 22161 

